\title{
Tempo e movimento: o futebol na pintura brasileira
}

\author{
Time and movement: football in Brazilian painting
}

Lucia Teixeira

Universidade Federal Fluminense (UFF), Niterói / Brasil Doutora em Linguística e Semiótica, USP

luciatso@gmail.com

Resumo: 0 artigo discute modos de dar visibilidade estética ao movimento desencadeado num campo de futebol e em seus entornos sócio-históricos. Para isso, analisa trabalhos de Djanira, Portinari, Rebolo, Claudio Tozzi, Nelson Leirner e OSGEMEOS, detendo-se na questão da presença sensível que institui um ritmo na articulação entre o tempo, o espaço e o corpo do sujeito. As imagens de diferentes momentos históricos da arte brasileira, analisadas sob a perspectiva da semiótica plástica, permitem reconstituir uma linha temporal que associa o futebol a paixões que vão da idealização romântica ao pragmatismo do mercado.

PalaVRas-chave: Futebol; Pintura brasileira; Presença; Semiótica plástica.

ABSTRACT: The article discusses ways to give aesthetic visibility to the movement unleashed on a football field and in its socio-historical environments. It analyzes the works of Djanira, Portinari, Rebolo, Claudio Tozzi, Nelson Leirner and OSGEMEOS, focusing on the question of the sensitive presence that establishes a rhythm in the articulation between time, space and the body of the subject. The images of different historical moments of Brazilian art, analyzed from the perspective of plastic semiotics, allow us to reconstitute a temporal line that associates football with passions that go from romantic ideation to market pragmatism.

KEYWORDS: Football; Brazilian painting; Presence; Plastic Semiotics. 
A meta da análise do gesto de pintar não é eliminar o problema da pintura. É penetrar o enigma da pintura, a fim de poder vivenciá-lo de forma sempre mais rica. [...] Por ser penetração do gesto, a análise não é ela própria gesto externo ao gesto analisado.

0 gesto de pintar pode ser decifrado como uma das fases de um gesto colossal coletivo, denominável 'o gesto da história', se definirmos 'história' por 'o movimento da liberdade'.

Gestos, Vilém Flusser.

As duas citações de Vilém Flusser introduzem o tipo de trabalho que aqui se apresenta sobre futebol: menos sobre jogo e mais sobre pintura, este texto discute modos de dar visibilidade estética ao movimento desencadeado num campo de futebol e em seus entornos sócio-históricos. Não me afasto, na verdade, do jogo em si, porque também na tela, nas cores e num certo arranjo de formas pulsa o movimento de uma presença afirmada como fenômeno de linguagem com seu caráter simbólico e passional. Mais ainda, a pintura retém do futebol o essencial de sua qualidade gestual e linguageira, dele fazendo representações que capturam o figural, o mais abstrato traço reiterado em sucessivos impulsos do corpo. No campo, os jogadores em movimento, as marcações espaciais de limites e direções, a bola em jogo e o espectador em tensão de corpo e voz, tudo põe em cena o corpo. Essa gestualidade intensa, concreta, sensorial ganha na arte a síntese capaz de restituir a presença plena do sentido.

Flusser, ao associar o pensamento ao movimento das mãos, oferece chave de compreensão para o esquematismo figural que a linguagem acaba por fazer de toda gestualidade:

Para compreender como pensamos, devemos observar as mãos: como os dedos movem, como o polegar se opõe aos demais dedos, como a mão se abre em palma e fecha em punho e como a mão direita espelha a esquerda. [...] 0 movimento das nossas mãos parece caoticamente complexo. Mas se pudéssemos fixar todos tais movimentos em fitas de vídeo, descobriríamos a gestalt da totalidade dos movimentos. Com efeito, dispomos de tal fita. É ela o universo dos artefatos humanos, a cultura. ${ }^{1}$

\footnotetext{
${ }^{1}$ FLUSSER. Gestos, p. 82.
} 
O corpo em si, significado em artefatos linguageiros, só pode estar no objeto semiótico como presença-síntese, forma poética que concentra e expande os sentidos. Um locutor de jogo de futebol faz isso, da mesma maneira que um pintor, um poeta, um escultor. Por meio de diferentes formas de expressão, o jogo se reencena e provoca o corpo do espectador, faz vibrar e sentir, empolga, irrita, agita e mobiliza sensorialmente. 0 futebol se joga no campo, mas também na tela, no papel, na voz, nos diferentes suportes materiais que sustentam suas representações. É assim que a significação se produz, nessa oscilação entre "efeitos de presença" e "efeitos de sentido". ${ }^{2}$

A presença deve ser considerada na "problemática geral das relações do sujeito consigo mesmo mediante as modulações do sentido que ele confere a seu espaço-tempo"3 e, portanto, no quadro de uma enunciação que, no estado inicial de relação do sujeito com o mundo, aparece difusamente como imersão fórica num espaço tensivo, do qual emergirá um homem que fala, pinta, produz discurso e estabelece formas de interação.

Os dados tensivos oscilam numa escala entre espera e distensão, submetida à ação do tempo, marcado por um ritmo. 0 sujeito imerso no tempo é também o sujeito integrado a um espaço em que profundidade e superficialidade são os operadores da relação. Essa imersão fórica, estado inicial da relação do sujeito com o mundo, vai se manifestar em diferentes níveis no percurso de busca de valores empreendido pelo sujeito: como emoção, síncope da duratividade, como paixão efeito da duratividade; como um sentimento, que assegura e torna lento um estado durativo; como ação, recorte narrativo sobre o fundo da temporalidade e da espacialidade; como discurso, realização totalizante e concreta de todas as possibilidades. Este é o percurso tensivo que põe em destaque o corpo do sujeito, afetado pelos acontecimentos. Um "friozinho na barriga", um "tremor", um "aperto no coração" são formas condensadas de expressar na linguagem os fenômenos de intensidade que o corpo sente na sua relação com o mundo. Estar num estádio e chorar com a perda de um título ou juntar-se ao coro de vozes que celebram uma

\footnotetext{
${ }^{2}$ GUMBRECHT. Produção de presença, p. 22.

${ }^{3}$ LANDOWSKI. Modos de presença do visível, p. 71.
} 
vitória ou exaltam uma jogada são formas de expressão corporal, gestual, de um sujeito afetado sensorialmente pelo acontecimento.

A pintura restabelece para o sujeito os afetos que o atingem e transformamse na cena do futebol. E só pode fazê-lo, porque toma do acontecimento o que lhe é essencial, mais profundo e esquemático. As predicações, as aspectualidades, a figuratividade, o estilo, as marcas do plano da expressão indicarão aquilo que afetou o sujeito em seu movimento no mundo e o modo como esses afetos, paixões, arrebatamentos, ritmos, gradações disseminam-se e concretizam-se na materialidade do discurso.

$\mathrm{Na}$ história da pintura brasileira, imagens de diferentes momentos permitem reconstituir uma linha temporal que associa o futebol a paixões que constroem, no imaginário nacional, um percurso que vai da idealização romântica ao pragmatismo do mercado. "Futebol”, um desenho de Djanira (Avaré/SP, 1914 Rio de Janeiro, 1979), imagem muito singela, de grande lirismo, simplicidade e contenção de recursos, pode ilustrar bem o primeiro desses momentos (Fig. 1).

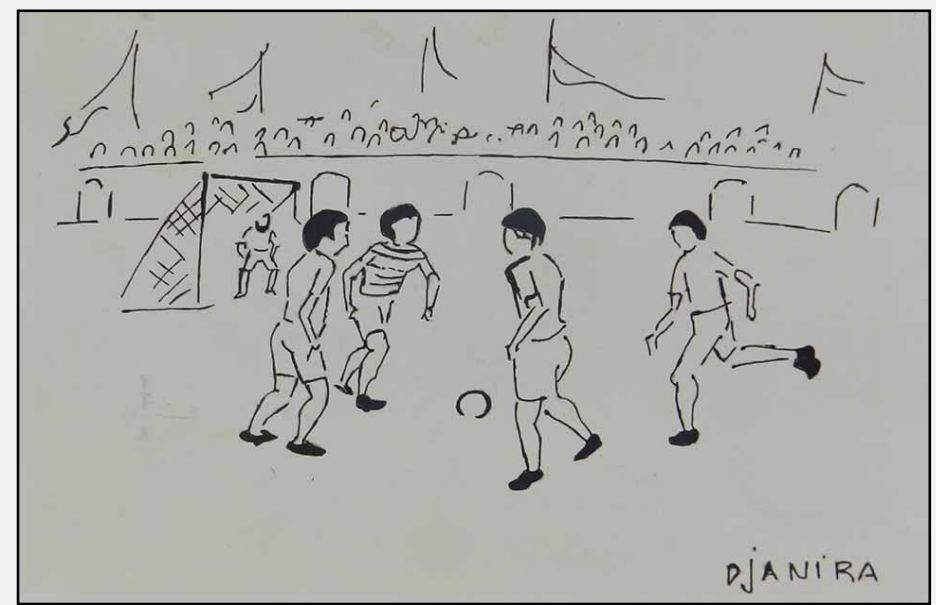

Fig. 1: Futebol, Djanira.

Henri Michaux (2001) foi quem classificou as linhas em viajantes e penetrantes: as primeiras passeiam, mostram trajetos mais que objetos; as segundas, segundo ele, estão "ávidas para envolver, fechar", são fazedoras de formas. 0 traço ingênuo de Djanira mostra que há muito as análises não podem mais ser feitas por meio de oposições estanques, mas é bem verdade que uma oposição pode ser um bom começo de método para a busca do sentido. 0 desenho 
retrata o jogo num estádio. Há, diante do gol e do goleiro, um grupo de quatro jogadores em torno da bola em posição de jogo. Ao fundo, a plateia, sugerida em traços curvos mal-acabados, entremeados por bandeiras agitadas. As linhas que constroem os jogadores se aproximam das penetrantes - traços mais firmes, formas reconhecíveis em figuras como jogadores, goleiro, bola, rede. Já o público do jogo vem sugerido em linhas viajantes, traços soltos e curvilíneos, apressados, sugerindo cabeças e, sobre elas, bandeiras tremulantes. A diferença está mais na aspectualidade do traço que no formato próprio da linha e na diferença substancial que existiria entre elas, desfeita na harmonia da cena.

Os traços que constituem as figuras principais, em primeiro plano, reproduzem a duração de um "durante", um momento que acontece diante dos olhos, a ação do jogo em andamento. À velocidade esperada do jogo, no entanto, se contrapõe a lentidão das figuras, acentuada pela concentração dos jogadores em torno da bola e pela configuração espacial do desenho. A tensão entre o programa narrativo do jogo e o ritmo do gesto enunciado se impõe numa certa hesitação da mão que desenha, num inacabamento que se acentua quanto mais longe vão os olhos. 0 efeito de inacabamento obtido pelas figuras que estão na plateia, apenas bandeiras e cabeças esquematizadas, é dado por linhas segmentadas, interrompidas e descontinuadas que se associam à aceleração do gesto enunciativo. Em contraparte, o espectador deve promover uma desaceleração para preencher o desenho de memória e significado. 0 olhar então, arrebatado por um primeiro golpe que fixa a atenção no grupo principal, descansa em seguida na extensão do desenho, no preenchimento do espaço, para obter o efeito global da cena. Já na ação principal, entretanto, há equilíbrio entre rapidez e lentidão. Se na bola, no braço dos jogadores e nos seus corpos as formas não se completam em relação à referencialidade do mundo concreto, fazendo divagar o olhar do espectador, os cabelos e os pés, sujeitos operadores das jogadas permitidas no campo, têm o preto contínuo e saturado como forças de retenção, reduplicadas no traço mais espesso das traves do gol e na organização topológica determinada pela delimitação entre os espaços do campo e da plateia. Essa oscilação rítmica entre a duração e a subitaneidade, dada pela oposição de recursos expressivos de retenção 
(reforço e continuidade do traço) e expansão (afinamento e descontinuidade do traço), é que produz o movimento da cena.

A pintura, segundo Aumont, inscreve "o vestígio de fenômenos temporais nas formas espaciais". ${ }^{4} 0$ famoso Fla x Flu, de Djanira (Fig. 2), captura o momento crucial de um jogo com a fabulosa inversão de ponto de vista que coloca o espectador dentro do gol, acompanhando a jogada.

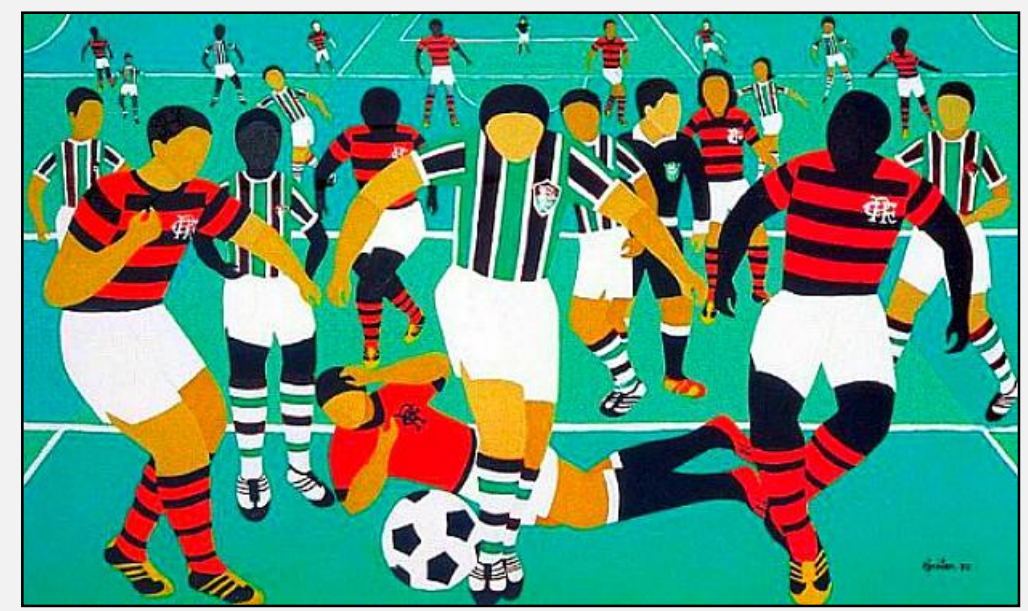

Fig. 2: Fla $\times$ Flu, Djanira.

Aqui são os efeitos de proximidade e distanciamento, criados pelos planos, as formas e as cores, que operam a relação com o espectador, inscrevendo o momento do chute a gol como presença sensível na tela. Todos os jogadores estão de frente para o espectador, e isso se identifica pela postura dos corpos, nunca pela definição de rosto ou olhar de algum deles. 0 jogador caído horizontalmente faz o contraponto com a verticalidade dos demais, trazendo o olhar do observador para a bola e o gramado. É desse modo que ele pode apreender a cena em sua totalidade, desviar-se do jogador flamenguista que domina a bola e abarcar o jogo. Por um lado, o ponto de vista enunciativo, que coloca o observador dentro do quadro, acelera o ritmo e fecha o foco dramático. Por outro, a convencionalidade das cores de uniformes e gramados e a distribuição das figuras restitui, pelo cromatismo e pela organização topológica, um fechamento e contenção ao tratamento do tema, deslocando-o para a desaceleração e para a abertura do foco.

\footnotetext{
${ }^{4}$ AUMONT. O olho interminável, p. 140.
} 
Djanira, no desenho e na pintura, está associada ao componente naif que trazia para o modernismo tardio o tanto de nacionalismo ingênuo que incorporava à temática das artes a chamada cultura popular. Com mais refinamento e igual vocação lírica, Portinari (Brodósqui/SP - Rio de Janeiro, 1962) já havia acolhido, na tela Futebol (Fig. 3), o futebol de várzea em quadro que associa a ingenuidade lúdica da temática ao refinamento estético da composição.

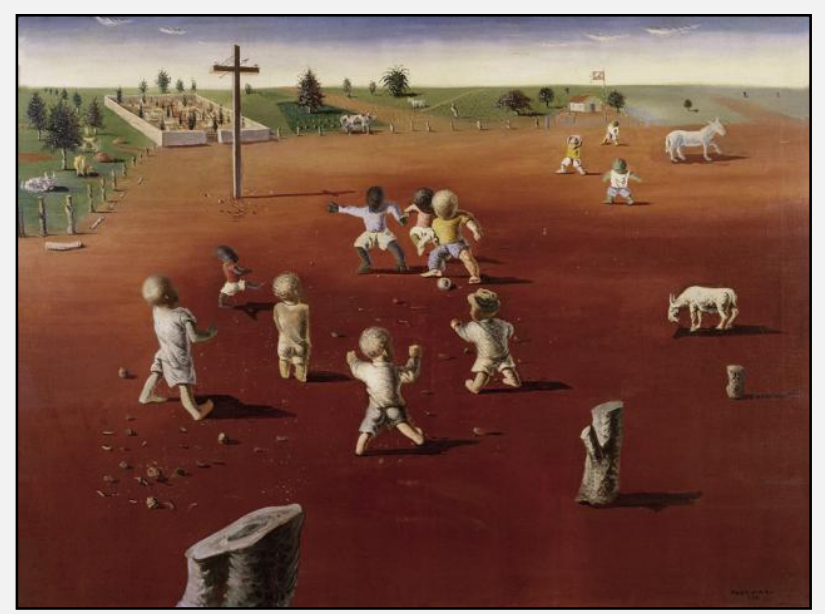

Fig. 3: Futebol, de Portinari.

Sobre a superfície horizontal do campo avermelhado das terras de Brodósqui, que preenche quase a totalidade do espaço da tela, o pintor paulista lança os pequenos jogadores em narrativa que pode ser refeita. No prédio à extrema direita do quadro, com a bandeira brasileira hasteada, pode-se imaginar a escola, o fim das aulas, os meninos que saem para casa e se demoram no caminho, jogando bola.

Há uma linearidade temporal das ações que se reflete na organização espacial ordenada com os tocos de árvores limitando o terreno, as linhas retas do muro do cemitério se harmonizando com a ordem que se reflete também nas árvores enfileiradas, nas pequeninas estradas retas e na grande cruz que isola o cemitério da brincadeira, demarcando os campos da morte e da vida. No centro do quadro, o grupo de jogadores figurativiza a entrega do corpo à bola e ao campo. Temos aí a intensificação da cor marrom avermelhada, o contraste entre a concentração da cor na terra e a dispersão nos tons claros das roupas dos meninos, verticalizados, em movimento, vida que se ergue da terra. A cruz, com a 
intersecção de verticalidade e horizontalidade, faz a distinção de campos e de sentidos. 0 campo santo e o campo do jogo não se misturam. 0 limite da cruz é o limite entre vida e morte para além do pequeno cemitério e de todas as formas de vida da pequena cidade: os meninos, os animais, árvores, plantações, construções. Figurativamente há limites claros, esparsos, a acentuar a exacerbação das qualidades de vigor e movimento das crianças, que desafiam a morte e preenchem de alegria a tela.

Que crianças são essas retratadas? São crianças só com braços e pernas. Sem rosto, sem contorno de feições, sem demarcações claras, os meninos de Portinari são puro movimento. Distribuídos aleatoriamente, muito agrupados ou dispersos, coloridos em branco com pontuações amarelas, azuis e algum vermelho, deixando a forma esférica da bola diminuir-se no confronto com a esfericidade aumentada das cabeças sem traços, esses meninos são pura figuração do caráter lúdico do jogo, do prazer da bola e do gesto. Ocupam uma linha diagonal central no quadro, que separa não só a vida da morte, mas a humanidade da animalidade e põem em relevo o "substrato autenticamente lúdico do jogo e a margem de certa gratuidade irredutível que ele guarda". ${ }^{5}$ Os meninos deixam então de ser personagens de uma narrativa e se tornam algo mais que figuras de uma cena cotidiana, tornam-se acontecimento, põem em cena a superação da rotina pelo acontecimento estético, que não está na figurativização da cena, mas na plasticidade da pintura.

Essa compreensão traz nova dimensão ao quadro, inscreve uma estrutura concessiva na placidez da cena, tensiona a linearidade e o ordenamento do espaço, põe abaixo a organização implicativa. 0 tempo de observação do quadro, tempo inscrito na pintura, passa do modo da desaceleração para o da aceleração, da percepção da totalidade para a particularidade, do entorno para o centro, do inteligível para o afetivo. Os meninos transformam-se em imagens, em recordação, em memória afetiva que entra na tela como puro efeito plástico, destituído da figuratividade concreta de rostos e identidades. Desfigurados são a vida que se contrapõe à morte, desidentificados, esses meninos são todos os meninos e

\footnotetext{
${ }^{5}$ WISNIK. Veneno remédio, p. 33.
} 
quaisquer meninos. A aceleração da percepção reflui no espectador como perenidade, como possibilidade de permanência da vitalidade, esperança que engana o vazio e vence a ausência de sentido.

Discípulo de Portinari, Francisco Rebolo (São Paulo, 1902-1980) representa talvez o exemplo mais curioso de artista brasileiro amante de futebol e pode funcionar aqui como uma transição estilística entre o modernismo e a arte pop dos anos 70. Jogador ele mesmo do Corinthians, pintou seu autorretrato em cena memorável de jogo Futebol (Fig. 4) em que dois jogadores se enfrentam, cercados pela sugestão do público em volta.

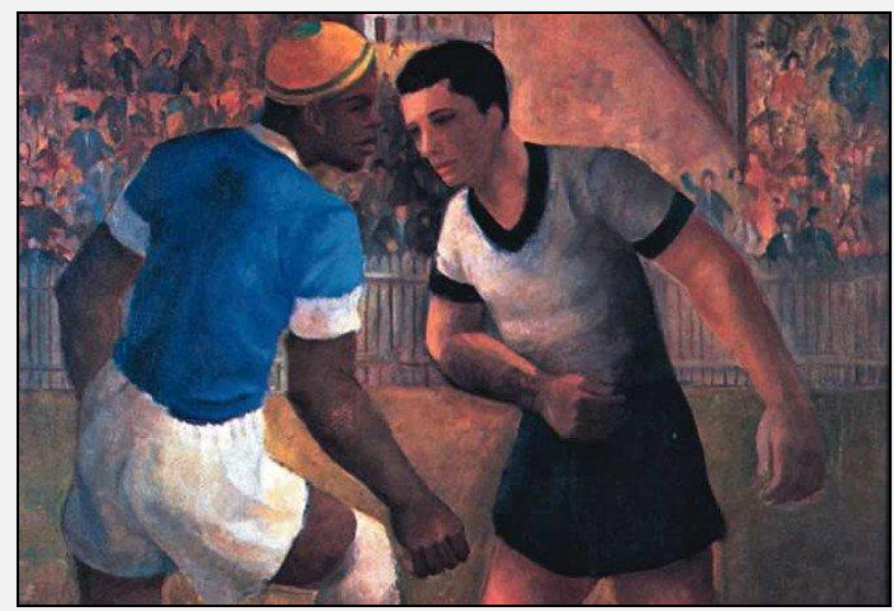

Fig. 4: Futebol, Rebolo.

Aqui são o cromatismo, sob intervenção da pincelada, e a organização topológica, com os planos, que se definem pela nitidez e apagamento de contornos, que produzem os efeitos de impacto. 0 lirismo da contemplação em Djanira e Portinari é substituído pela sensualidade da aproximação em Rebolo. Tudo nesse primeiro plano aproxima o espectador da cena: os corpos dos dois jogadores em gestualidade solta, próximos a ponto de quase se encaixarem; pernas e braços no ar, sugerindo movimento em andamento; as cores dos uniformes bem definidas; rostos bem delineados. Quase se pode ouvir o silêncio de um segundo da expectativa da jogada, preso nas imagens indefinidas do público, transformado numa espetacular massa cromática diluída, indefinida, separada ao meio pela luz que atravessa gramado e cena. 
O foco sobre a disputa entre os dois homens, acentuado pela iluminação difusa, que desce do rosto para as pernas dos jogadores, concentra a observação na jogada, destacando o balé extraordinário do desafio e da disputa. Mas a luz de fundo movimenta o olhar do espectador para longe, para o céu e o cenário, até retornar para a plateia, a massa de torcedores feita de mistura cromática diluída e formas indefinidas. 0 rebatimento cromático entre plateia e gramado traz novamente o olhar para o par de jogadores, na cena principal. 0 percurso de observação do quadro parece reduplicar as emoções do estádio. Entre concentração e expansão dos movimentos formais da pintura, o espaço se define como lugar de valorização da individualidade dos jogadores e de suas habilidades particulares.

A arte moderna parece aproximar-se do futebol, conferindo-lhe a beleza de formas e movimentos que o instalou no imaginário brasileiro em cenas sempre repetidas, relembradas, romantizadas. Captura momentos de jogo, amplia o espaço, associa público e jogadores. Numa citação de Rebolo, perenizada em placa no estádio do Pacaembu, talvez esteja a melhor síntese de uma concepção que hoje nos parece simplória de arte e de futebol: "Antes da pintura, o futebol já tinha marcado minha vida. Como no futebol, acho que na arte devem-se fazer coisas espontâneas, com a marca do amor e do entusiasmo, para poder se emocionar e emocionar outras pessoas". 6

O Rebolo do autorretrato é este das palavras, feito de emoções individuais e sentimentos benevolentes. Há força nos jogadores da pintura, mas há delicadeza nos gestos, bailado em contraposição a brutalidade, leveza em vez de dureza. Talvez esteja aí uma visão que hoje se considera ingênua do futebol, de um tempo em que os ídolos tornavam-se reis que tudo podiam, capazes de entregar aos torcedores momentos de vitória e felicidade.

Não tão ingênua, a arte pop capta o puro movimento plástico da cena do jogo, isola jogadores e destaca jogadas para transformar o futebol em vibração cromática, gestualidade e celebração do gesto individual, esta já prenunciada em Rebolo. Basta lembrar do voo espetacular do goleiro Gilmar, na tela de Gerchman

\footnotetext{
${ }^{6}$ GONÇALVES. Lisbeth R. [Entrevista].
} 
(Rio de Janeiro, 1942-São Paulo, 2008), que choca pelo inusitado aparente para, logo adiante, remeter diretamente a fotografias repetidas nas páginas de jornais cotidianos. Aqui são os vazios que preenchem o quadro de possibilidades, da brevidade do gesto inventam-se narrativas possíveis. Mais uma vez, a sobreposição do verbal trava a expansão das interpretações. Gilmar é o goleiro que todos conhecem. Some-se a isso o fato de que a tela se inscreve numa série dedicada a jogadores em que se reafirma uma identidade figurativa concreta, personalizada. Gilmar é mais um dos "heróis" que Gerchman pintou em quadros que recusam a exuberância de cores do pop americano e fixam a representação no movimento e no gesto.

A memória do espectador é acionada, o tempo se desacelera, os quadros vão compondo um painel de nomes, rostos e ações ligados por implicações lógicas. A concessão do movimento cede à lógica da narrativa e a pintura volta ao real concreto do mundo para apropriar-se de sua qualidade figurativa. Autor de uma série de retratos e cenas do futebol, Gerchman capturou momentos e estrelas do esporte em cenas antológicas em que se abandona o lirismo pela focalização do instante. A pintura é prospectiva, sugere possibilidades, como o jogo. É Wisnik quem afirma: "No futebol temos uma sequência contínua e inumerável de alternativas em que o avanço numérico é um acontecimento entre outros, que se destaca de um magma de possibilidades não cumpridas, de um vai e vem de lances falhados ou belos em si".7

Claudio Tozzi (São Paulo, 1944), em A dança do futebol (Fig. 5), opera com as cores primárias, o preto e o branco, para distribuir na tela pernas e corpos em movimento. 0 efeito de vivacidade criado pelo aspecto de inacabamento e rapidez do traço, pelas zonas de cor sem gradação em contraste, e a superposição de formas associa-se ao voo de Gilmar para mostrar que a celebração do futebol se concentra nas disputas individuais e no forte apelo dos gestos brilhantes de parcerias combinadas.

\footnotetext{
${ }^{7}$ WISNIK. Veneno remédio, p. 19.
} 


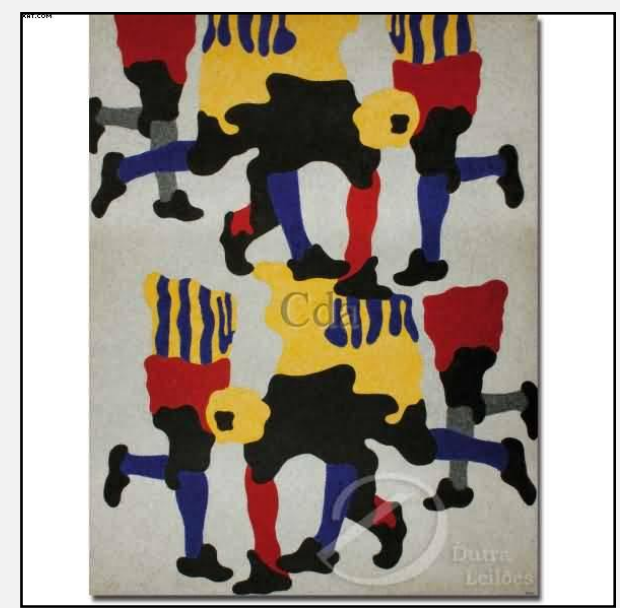

Fig. 5: A dança do futebol, Tozzi.

0 triunfo desse enaltecimento da performance individual sobrepõe-se, na arte contemporânea, ao que havia ainda de exaltação da beleza plástica do jogo, seja pelo apagamento do próprio jogo, na representação subversiva de Nelson Leirner (São Paulo, 1932), seja pelo deslocamento da pintura para suportes mais midiáticos, na fina fronteira entre arte e publicidade d'OSGEMEOS (São Paulo, 1974). Em Leirner, figuras do universo pop e atores religiosos tomam a cena em maquetes que negam o jogo, tal como convencionalmente é dado a ver, para afirmá-lo em valores abstratos como devoção, religiosidade, carnavalização etc. Os jogadores vestem as túnicas dos santos e a plateia se divide entre figuras de HQs, super-heróis, princesas e nossas senhoras.

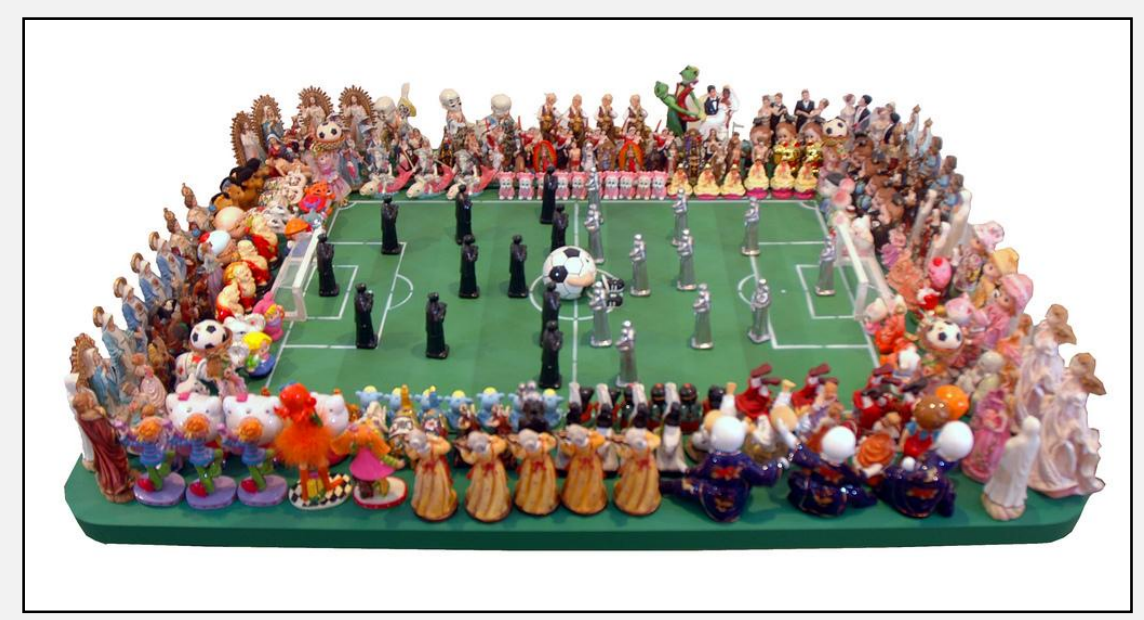

Fig. 6: Futebol, Leirner. 
Curiosamente, nessa representação de figurativização subvertida, há um arranjo ordenado e disciplinado dos elementos, estando na tensão entre desarranjo (com o deslocamento de isotopias temáticas e figurativas) e disciplina (da representação), e, portanto, no conflito entre enunciado e enunciação o efeito de humor. Também apelando para o humor e ampliando a espetacularização da representação, a dupla de grafiteiros OSGEMEOS, alçada recentemente ao nobre recinto dos museus e galerias e à glória do reconhecimento do mercado de artes, pintou o avião da seleção brasileira de futebol (2014). Sob a forma de grafite, em que pretenderam representar "a população brasileira com sua etnia tão diversa e colorida" (entrevista dos gêmeos ao Globo esporte, 2014), OSGEMEOS transformaram o avião em suporte, pintado com tinta industrial, escadas, andaimes e todo um aparato monumental de trabalho e divulgação. Preservada a logomarca da Gol e garantida a publicidade dos voos nos céus do planeta, o trabalho garante seu vínculo com o mercado e o trânsito entre espetacularização estética e propaganda.

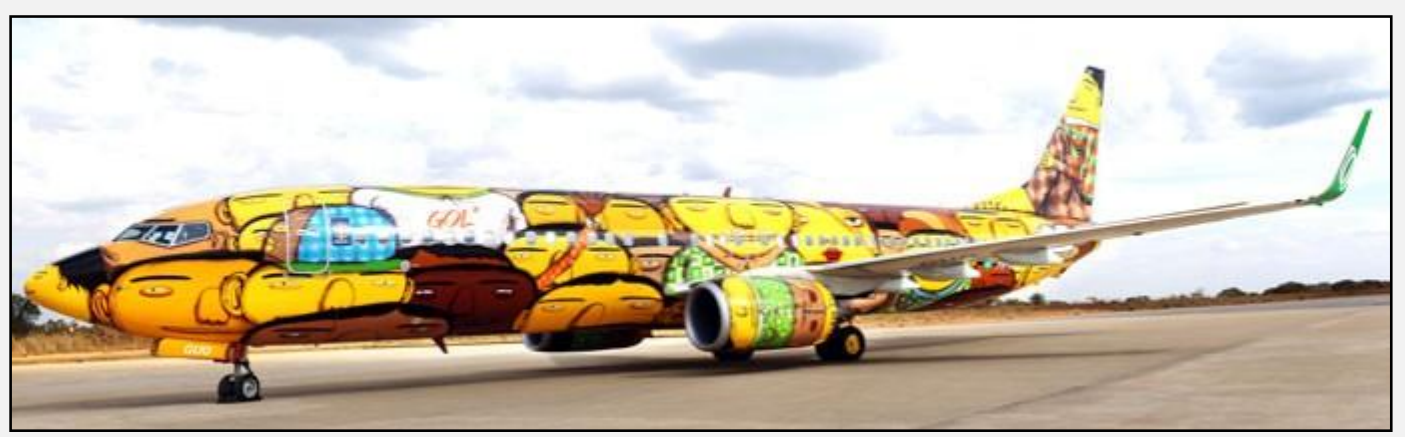

Fig. 7: pintura d'OSGEMEOS no avião da seleção.

A vivacidade das cores, o acúmulo de figuras, o gigantismo do suporte, a submissão da pintura à marca (nos elementos figurados, na preservação da logomarca e na coisa em si): tudo aqui é da ordem do excesso, do mirabolante, do exagero. Na tênue fronteira que hoje se estabelece entre artes visuais e publicidade, que desmancha a célebre oposição de Valèry entre valores estéticos e utilitários, o futebol se dobra ao imperativo do marketing, e a arte também se submete a essa mudança.

Talvez possamos estabelecer aqui uma relação entre a representação historicamente mutante do futebol na pintura e o modo de ser do esporte ao longo 
dos anos no Brasil. Preso ainda a um imaginário lírico e ingênuo, que preserva a pelada e o futebol de várzea, o futebol hoje anda no avião do mercado, que desaparece com os jogadores, o jogo, a cena dramática e libertadora. Se o que resta do futebol na arte contemporânea é a subversão dos atores, como em Leirner, ou a compreensão dos apelos do mercado e da espetacularização da marca, como nos Gêmeos, os bons sentimentos de Rebolo e Portinari, o lirismo de Djanira, os heróis de Gerchman e o apelo sensorial da arte pop talvez estejam ainda mantidos na imaginação dos torcedores que consideraram o avião pintado "uma palhaçada" ou "um sucatão".

A paixão que torna rei um jogador não está distante daquela que menospreza novos formatos da arte e novas regras do jogo. De toda maneira, pulsa ainda o coração do torcedor, e a arte, em sua infinita falta de jeito para a submissão, restitui ao jogo seu caráter simbólico e libertador.

\section{REFERÊNCIAS:}

AUMONT, Jacques. O olho interminável - cinema e pintura. São Paulo: Cosac Naify, 2004.

CLAUDEL, Paul. L'oeil écoute. Paris: Gallimard, 2003.

FLUSSER, Vilém. Gestos. São Paulo: Annablume, 2014.

FONTANILLE, Jacques; ZILBERBERG, Claude. Tensão e significação. São Paulo: Humanitas, 2001.

GONÇALVES, Lisbeth R. São Paulo, 28 abr. 2009. Entrevista [concedida a Regina Rocha]. Disponível em: <goo.gl/8quCjE>. Acesso em: 23 set. 2016.

GUMBRECHT, Hans Ulrich. Produção de presença: o que o sentido não consegue transmitir. Rio de Janeiro: Contraponto: Ed. PUC-Rio, 2010.

LANDOWSKI, Eric. Modos de presença do visível. In: OLIVEIRA, Ana Cláudia de. Semiótica plástica. São Paulo: Hacker, 2004, p. 97-112.

MICHAUX, Henri. Oeuvres completes, tomo 2. Paris: Gallimard, 2001. [Collection La Pleiade].

MORAIS, Frederico. Futebol e arte. In: SEFFRIN, Silvana (org.). Frederico Morais. Rio de Janeiro: Funarte, 2004.

PEREIRA, Felipe. Avião da seleção na Copa do Mundo terá pintura dos grafiteiros OSGEMEOS. UOL, São Paulo, 26 maio 2014. Disponível em: <goo.gl/luZeVB>. Acesso em: 16 set. 2016. 
PORTFOLIO BRASIL. Artes plásticas. Rubens Gerchman. São Paulo: J. J. Carol, 2007.

TEIXEIRA, Lucia. Notas para um estudo do ritmo nas semióticas visuais. Coleção Mestrado em Linguística - dossiê Sentidos em movimento: identidade e argumentação, São Paulo: UNIFRAN, 2008, vol. 3, p. 159-180.

TEIXEIRA, Lucia. Ritmos do futebol na pintura brasileira. In: MENEZES, Raquel; MIRANDA, Fernando (orgs.). Pequena morte - futebol-arte. Rio de Janeiro: Oficina Raquel, 2010, p. 39-45.

WISNIK, José Miguel. Veneno remédio: o futebol e o Brasil. São Paulo: Companhia das Letras, 2008.

ZILBERBERG, Claude. Du tempo en peinture. Actes Semiotiques, Limoges, n. 118, 2015. Disponível em: <epublications.unilim.fr/revues/as/5508>. Acesso em: jan. 2016.

ZILBERBERG, Claude. Síntese da gramática tensiva. Significação: Revista de Cultura Audiovisual, São Paulo, vol. 33, n. 25, 2006, p. 163-204.

ZILBERBERG, Claude. Observações sobre a base tensiva do ritmo. Trad. Lucia Teixeira e Ivã Carlos Lopes. Estudos semióticos, São Paulo, vol. 6, n. 2, 2010, p. 1-13. Disponível em: goo.gl/Ukjv6T. Acesso em: jan. 2016.

\section{OBRAS VISUAIS:}

DJANIRA. Futebol. Nanquim sobre papel. 16x24cm. Disponível em: goo.gl/4gqSDV. Acesso em: 23 jul. 2016.

DJANIRA. Fla x Flu (1975). Acrílica sobre tela. 96 x 161,5 cm. Rio de Janeiro: Museu Nacional de Belas Artes. Disponível em: goo.gl/27UWGs. Acesso em: 23 jul. 2016.

LEIRNER, Nelson. Futebol (2000). Maquete. 120x90cm. Disponível em: goo.gl/GiFEho. Acesso em: 23 jul. 2016.

OSGEMEOS. Avião da seleção [grafite]. In: PEREIRA, Felipe. Avião da seleção na Copa do Mundo terá pintura dos grafiteiros OSGEMEOS. UOL, São Paulo, 26 maio 2014. Disponível em: goo.gl/luZeVB. Acesso em: 16 set. 2016.

PORTINARI, Cândido. Futebol (1935). Óleo sobre tela. 97x130cm. Coleção particular. Disponível em: www.portinari.org.br/\#/acervo/obra/1127. Acesso em: 23 jul. 2016.

REBOLO, Francisco. Futebol (1936). Óleo sobre tela. 86x36cm. Disponível em: goo.gl/s6ju06. Acesso em: 23 jul. 2016.

TOZZI, Claudio. A dança do futebol (1997). Acrílica e óleo sobre tela. 245x190cm. Disponível em: goo.gl/DUp2Bd. Acesso em: 23 jul. 2016.

Recebido para publicação em 19 ago. 2016

Aprovado em 02 nov. 2016 